\title{
Effectiveness of a Gamified Mobile Learning Environment
}

\author{
Rexcel Cariaga \\ De La Salle - College of Saint Benilde, Philippines
}

\begin{abstract}
With today's fast pace of life, mobility in learning is quickly becoming an essential necessity in the 21st century education. Through mobile learning, anyone can view educational materials in his or her smartphone or tablet. However, while mobile learning makes it easier for the students to access the lessons anytime and anywhere, a lot of students still spend more time playing games on their mobile devices. This research examines the effectiveness of a gamified mobile learning environment inside the college classroom to engage the students in the learning process
\end{abstract}

Keywords: mobile learning, gamification, games, game-based learning, hybrid education

\section{Introduction}

Mobile devices have changed the way people live. Aside from primarily using smartphones and tablets for communication, people use them to play games, book a taxi, navigate around the roads, surf the internet or simply use these devices as a watch or an alarm clock. With the use of these devices, communication and information is readily available anytime and anywhere paving the way for mobile learning or m-learning.

There is a misconception, however, that mobile learning is part of e-learning. e-Learning is designed for the learner to sit in front of the computer or laptop and progress through a specified amount of material and time. e-Learning courses are offered in a formal and structured manner while m-learning courses allow students to learn in an informal and opportunistic approach.

Although mobile learning makes it easier for the students and teachers to communicate with each other, a lot of students still spend more time playing games on their computers or on their mobile devices.

To solve this problem, game developers delved into game-based learning by creating educational mobile and computer games. These games have elements like rewards such as badges and points that the players receive in order for them to unlock new levels.

According to Rogers, games contain progression elements such as points, badges, and leader boards that make them addictive [6].

Game-based learning, however, is different from gamification. Gamification involves the use of game elements in a non-game scenario, particularly in an educational setting, in order to motivate the students to be active participants in the learning environment. Isaacs defined gamification as the idea of adding game elements to a non-game situation whereas game-based learning is learning through games [5].

In this study, the researcher ventured in gamifying a multimedia-programming course by rewarding the students with points and badges for their achievements along with their names appearing in the leader board rankings. Students were also able to access the lessons in their mobile devices or in their personal computers.

The research wanted to find out if mobile learning fused with gamification could significantly increase the students' learning performance.

\section{Theoretical Foundations}

This study is anchored on Kapps' theory of "Gamification of Learning and Instruction". According to Kapp, "gamification of learning is an educational approach to motivate students to learn by using video game design and game elements inside learning environments" [1]. Yuang and Soman also cited that the goal of gamification of learning is to maximize student engagement and enjoyment in learning [8].

With the use of game elements in a non-game context, gamification of learning can greatly influence the students' behavior and inspire them to continue learning. In a gamified learning 
environment, Levine discussed that students have the desire for status, power, and self-expression. This is shown in Levine's "Gamification of Engagement Loop" in Figure 1.

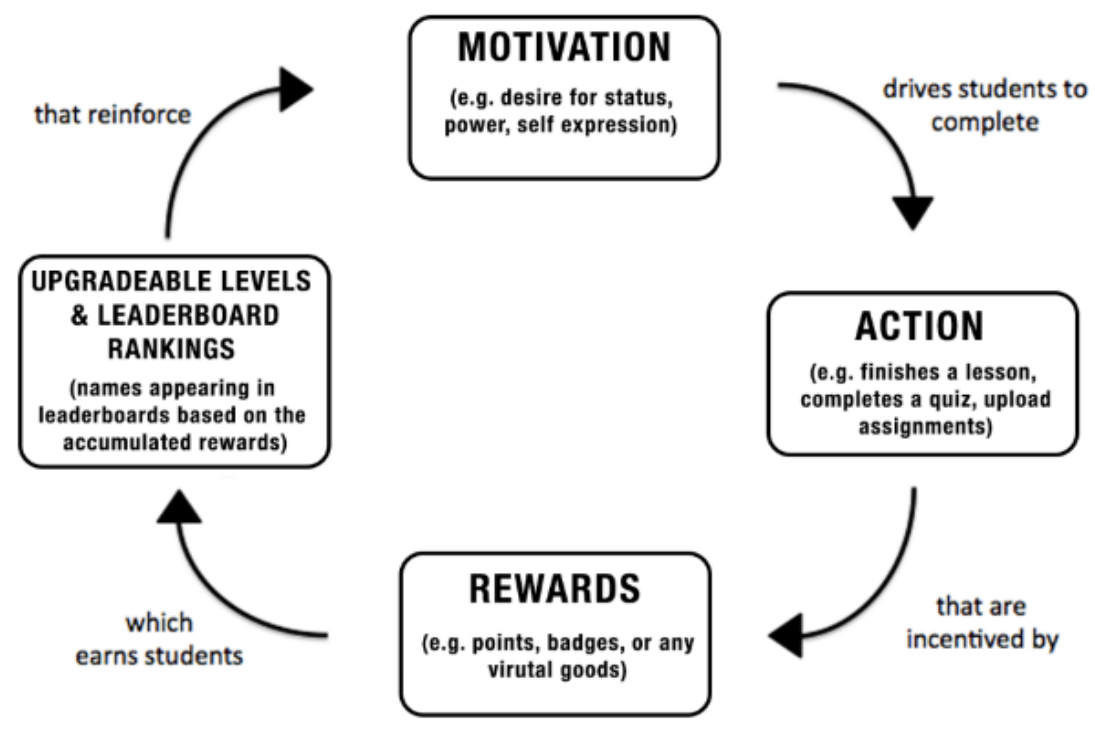

Fig. 1: The Gamification of Engagement Loop

Figure 1 shows that the student's desire for status, power, and self-expression drive them to complete a certain action in the learning environment such as uploading an assignment on time or finishing a lesson, which will be incentivized by various rewards. This rewards may be in the form of points, badges, or any virtual goods. As the student accumulates rewards, he or she upgrades a level making his or her name appear in the leader board rankings.

\section{Research Methodology}

The study ran during the month of September 2016. The respondents of the study were currently in their 3rd year college and have recently passed their logic formulation course, as a prerequisite for their multimedia-programming course. These students belonged to the middle to upper class members of the society and have been frequently playing mobile games.

The students were separated in two groups, the control group and the experimental group. The control group had access to instructional videos about multimedia-programing which they could access through their mobile phones or in their personal computers. The experimental group also had access to the same instructional videos. However, students in the experimental group were rewarded with points and badges every time they view a video lesson, submit an assignment, posts discussions, or answer tests online. Weekly face-to-face discussions were also conducted by the professor for both groups during the course of the study.

Pre-tests were conducted for both groups at the start of the term while the post-tests were conducted on the last week of September. The results that had been obtained from these tests were statistically computed using a t-Test in order to determine if a mobile and gamified learning environment significantly increased the academic performance of the students in the experimental group compared to the students in the control group.

At the end of the study, the researcher also interviewed the students in the experimental group to assess how the mobile and gamified learning environment affected their performance in the course. 


\section{Gamification Design}

The multimedia-programming course had four modules containing five to eight video lessons each. In order to enhance the informal structure of mobile learning, each video lesson ran for a maximum of five to ten minutes.

The first set of video module contained tutorials about the basic interface of Adobe Animate, as well as, basic navigational scripting. The next three set of video modules discussed about creating functions and coding variables and data types in ActionScript 3. Additionally, the modules also tackled about creating conditional statements and making symbols draggable in ActionScript 3. The students were required to submit an assignment after going through each module. These assignments were an e-card, an avatar-modification game, a click-and-shoot game and a 4-piece-puzzle game.

In order to access the gamified learning management system through a mobile device, students in the experimental group had to download the TalentLMS app from the Google Play or App Store.

Points were awarded to the student every time he or she interacted with the multimedia-programming course in TalentLMS. Every time the student logged in to the multimedia-programming course in TalentLMS, he or she gained 25 points. 25 points were also awarded to the student every time he or she viewed a video lesson. After viewing the video lessons in a certain module, a practice test is conducted in order to test the student's programming comprehension. For every successful test completion, 100 points were given.

For each assignment completion, 100 points were given. The first assignment in this course was an e-card that would demonstrate the basic scripting navigation in ActionScript 3. The second assignment in this course was a mobile game where the player can modify an avatar's position, width, height, scale, and transparency. This assignment demonstrated the modification of various symbol properties through scripting. The third assignment was a click-and-shoot game where players kill moving enemies by tapping or clicking them on the screen. This assignment demonstrated coding variables and data types in ActionScript 3. The fourth assignment in this course was a 4-piece puzzle game. This assignment demonstrated conditional statement scripting in ActionScript 3.

The student, while simultaneously earning points, also acquired activity badges, test badges, assignment badges, and communication badges.

The student could earn six different types of activity badges depending on the number of times they have logged in to the course in TalentLMS. A student was given an Activity Newbie Badge if he or she has only logged in for 4 times. If the student has logged in to the course for only 8 times, he or she received an Activity Grower Badge. An Activity Adventurer Badge was given to a student if he or she has logged in for 16 times. If the student has logged in to the course for the 32nd time, he or she was given an Activity Explorer Badge. Consecutively, the student could earn an Activity Star Badge if he or she has logged in for 64 times; and an Activity Superstar Badge was awarded to the student if he or she has logged in to the course for more than 128 times. Along with the Activity Badges, students could also acquire test badges.

In this study, the student could acquire two different types of test badges. Once a student has successfully completed two tests, he or she was awarded with a Test Newbie Badge. If the student, however, has successfully completed four tests, he or she was awarded with a Test Grower Badge.

Aside from the students being able to acquire various types of test and activity badges, he or she could also acquire different types of assignment badges. As this study comprised of four assignments, there were 4 different types of Assignment Badges that the student could earn. A student was awarded with an Assignment Newbie Badge upon submitting the e-card activity on or before the deadline. An Assignment Grower Badge was also awarded to the student upon submitting the avatar-modification game on or before the deadline. Consecutively, a student was given an Assignment Adventurer Badge upon submitting the click-and-shoot game and an Assignment Explorer Badge upon submitting the 4-piece puzzle game on or before the deadline.

Communication Badges were also awarded to the student every time he or she posted discussions or comments inside TalentLMS. There were six types of communication badges that the student could earn from this course. For the first two discussions or comments posted in TalentLMS, the student was given a 
Communication Newbi Badge. A Communication Grower Badge was awarded to the student upon posting 4 discussions or comments. Upon posting 8 discussions or comments, he or she was awarded with a Communication Adventurer Badge. When a student has posted a total of 16 discussions or comments, he or she earned a Communication Explorer Badge. Consecutively, a student could earn a Communication Star Badge upon posting 32 discussions or comments and a Communication Superstar Badge upon posting more than 64 discussions or comments. The number of points and badges that the student acquired determined his or her ranking in the leader board. The student upgraded to one rank level for every 200 points acquired. Alternatively, the student upgraded to one rank level for every badge acquired.

Students with the most points and badges and are in the highest-level appeared in the top leader board rankings.

\section{Profile of the Respondents}

Table I shows the profile of the respondents according to sex. The control group had 15 respondents while the experimental group had 14 respondents. While the sex of the respondents in the control group is almost evenly distributed, the experimental group is mostly composed of female respondents. This is shown by the 10 female respondents in the experimental group who comprise $71 \%$ of the total number of respondents in the said group.

TABLE I: Profile of the Respondents according to Sex

\begin{tabular}{lcc}
\hline Gender & $\begin{array}{c}\text { Control } \\
\text { Group }\end{array}$ & $\begin{array}{c}\text { Experimental } \\
\text { Group }\end{array}$ \\
\hline Male & 8 & 4 \\
Female & 7 & 10 \\
\hline Total & 15 & 14 \\
\hline
\end{tabular}

Table II shows the profile of respondents according to their length of engagement or frequency in playing mobile games.

TABLE II: Profile of the Respondents according to Length of Engagement in Mobile Games

\begin{tabular}{lcc}
\hline $\begin{array}{l}\text { Length of } \\
\text { Engagement }\end{array}$ & $\begin{array}{c}\text { Control } \\
\text { Group }\end{array}$ & $\begin{array}{c}\text { Experimental } \\
\text { Group }\end{array}$ \\
\hline Never & 1 & 0 \\
Occasionally & 7 & 11 \\
Always & 7 & 3 \\
\hline
\end{tabular}

Majority of the respondents in the experimental group occasionally or always play mobile games. This is shown by the 11 respondents who comprise $78.6 \%$ of the total number of respondents in the said group saying that they occasionally play mobile games. The other three respondents, who comprise $21.4 \%$ of the experimental group, show that they always play mobile games, whereas the respondents in the control group have equal number of students playing mobile games occasionally or always.

\section{Multimedia-Programming Course Test Results}

Table III shows the pre-test results of the respondents in the Multimedia Programming test.

TABLE III: Pre-test results of the respondents in the Multimedia Programming Test

\begin{tabular}{lcc}
\hline Pre-test results & $\begin{array}{c}\text { Control } \\
\text { Group }\end{array}$ & $\begin{array}{c}\text { Experimental } \\
\text { Group }\end{array}$ \\
\hline $\begin{array}{l}\text { Mean } \\
\text { Standard }\end{array}$ & 10.07 & 9.21 \\
Deviation & 1.75 & 4.84
\end{tabular}

The results of the respondents' pre-test scores shows that the mean score of the control group is higher than that of the experimental group as shown in Table III. Moreover, the pre-test scores of the experimental group are more varied than that of the control group as seen in standard deviation results, 1.75 for the control group and 4.84 for the experimental group. 
The big variation of scores among the respondents may have resulted from the students having different professors in their pre-requisite subjects, thus having a diverse set of knowledge about the subject matter. Additionally, some students may have taken the pre-requisite subject a few semesters earlier leading to a knowledge lapse of the subject matter; while some students have strictly taken the pre-requisite subject based on the prescribed curriculum timeline.

Table IV shows the post-test results of the control and experimental group after conducting 4 weeks of multimedia-programming lessons.

TABLE IV: Post-test results of the respondents

\begin{tabular}{lcc}
\multicolumn{3}{c}{ in the Multimedia Programming Test } \\
\hline Pre-test results & $\begin{array}{c}\text { Control } \\
\text { Group }\end{array}$ & $\begin{array}{c}\text { Experimental } \\
\text { Group }\end{array}$ \\
\hline Mean & 15.93 & 16.93 \\
Standard & 3.61 & 3.69 \\
Deviation & 3 \\
\hline
\end{tabular}

The mean score of the experimental group is now higher than that of the control group showing an improvement in their pre-test results. The post-test score variations between the groups have become more similar compared to their pre-tests results as seen in the standard deviation results, 3.61 for the control group and 3.69 for the experimental group.

The similar variation of post-test results between the groups resulted from the students having the same instructor conducting weekly face-to-face discussions, as well as, having access to the same video lessons. However, only the students in the experimental group were rewarded with points and badges for their accomplishments in the course.

The post-test results show that these game progression elements positively affected the performance of the students in the experimental group. However, a one-point difference in their mean shows that the teacher's presence was also a vital factor in motivating the students in both groups.

In fact, Ozuorcun and Tabak stated that while e- learning (control group) and m-learning (experimental group) may have the same technological advances in the 21 st century education, student motivation was a major problem in both learning models [8].

Table 5 shows the significant difference in the control and experimental group's multimediaprogramming post-tests results using a t-Test.

TABLE V: Difference in the control and

\begin{tabular}{lc} 
& experimental group's post-test results \\
\hline $\mathrm{N}$ & 15 \\
$\mathrm{df}$ & 27 \\
\hline sig & 0.05 \\
\hline $\mathrm{P}(\mathrm{T}<=\mathrm{t})$ & \\
one tail & 0.24 \\
\hline Interpretation & not significant \\
\hline
\end{tabular}

Table $\mathrm{V}$ shows that the computed value for the difference in the control and experimental group's post-test results is 0.24 with the degree of freedom of 27 at .05 level $(\alpha=0.05)$ level of significance. Although the mean scores of the experimental group is higher than that of the control group, the difference is not significant as shown by the one-tailed t-Test result.

Based on the researcher's focus group interview, one student said that being ranked at the bottom of the leader board in the gamified learning management system discouraged him to perform better in class. The student also said that it is very embarrassing for him that all of his classmates can see his ranking in the leader board.

Another student in the experimental group said that while the gamified learning management system allows you to earn rewards by posting comments and discussions, she hesitated to post questions inside the learning management system since Google provides a more instant access to information. This also true for the control group where the respondents in the said group can also access information online anytime and anywhere even without gamification rewards as motivational tools. Online communication can also happen outside TalentLMS through a more preferable social media platform, such as Facebook. 
Furthermore, while both groups had access to the same video lessons and activities, the results can be related to study of Law, Watkins, Barwick, and Kirk wherein applying gamification in academic institutions may not have a significant effect in the students' performance due to the individual preferences in games. According to the authors, games are not to everyone's liking [3].

Likewise, the respondents in the experimental group belonged to the middle to upper class of the society who have owned a smartphone for more than three years and have occasionally played mobile games. While the mobile and gamified learning management system provide points, badges, and upgradeable levels to the students, the students may have games installed in the mobile phones that provide them with more enjoyment and relaxation.

In addition, students said that while the rewards make the lesson quite enjoyable and fun, they would rather prefer to receive more substantial rewards such as an additional grade as this leads them closer to passing the course as opposed to points and badges that have no value in real life. As these students are currently taking up thesis writing and on their way to graduation, it may seem that these students are more focused into getting high or passing grades rather than getting game rewards which have little or no value in the real world.

Mollick and Rothbard even stated that when a player is required to accomplish something and supposed to make things fun, the idea of "fun-ness" is being violated. Instead of players voluntarily choosing to play any game they like that suits their personal interests, they are required to achieve a set of tasks [4].

The results of the study wherein computer-based training was switched to mobile-based training for the experimental group can also be associated with Kumar's study explaining that there are adaptability struggles in switching from traditional classroom training to computer-based training [10]. During the researcher's focus group interview, the students in the experimental group had a hard time getting accustomed to the mobile and gamified learning management system and suggested the the system's user experience should be improved.

\section{Conclusions and Recommendations}

During the course of the study, the results show that there was no significant difference in utilizing a mobile and gamified learning management system in the classroom environment as opposed to having access to video lessons. According to the respondents in the experimental group, the mobile learning management system was not very user-friendly. Students also had a hard time getting accustomed to the mobile learning environment. Leader boards also discouraged the students to perform better in the class especially when they are ranked at the bottom.

While both video lessons and a mobile and gamified learning management systems are educational tools suitable for the 21st century learning environment, the physical presence of the teacher is still an important factor in motivating the students to perform better inside the learning environment.

It is also recommended that mobile learning management systems should be more user-friendly and that members from academic institutions should be accustomed on how to use mobile learning tools.

Furthermore, leader boards in a gamified learning environment should be omitted as these may discourage students who are at the bottom of the ladder to perform better.

\section{Acknowledgements}

Venus Mariano, Amelia Paje, Danila Sabado, Norita Manly, Rainier Barcelona, Penn Bulaquena, Bradley Go, Brandon Go, Ysabel Moro, Ross Ann Oliveros, Francis Ramos, Mary Santos, Nicole Valencia, Ysabel Victoriano

\section{References}

[1] B. Levine (May 2013), "It's Not Gamification. It's How You Use It", Available: http://www.cmswire.com /cms/customer- experience/forrester-report-its-not-gamification-its-how-you use-it-020926.php

[2] K. Kapp, The Gamification of Learning and Instruction, Pfeiffer, San Francisco, California, 2012. 
[3] E.Law, D. Watkins, J. Barwick and E. Kirk, "Gamifying Research on Children's Understanding of Law in Their Lives”, University of Leicester, United Kingdom, 2014.

[4] E. Mollick and N. Rothbard, Mandatory Fun: Consent, Gamification, and the Impact of Games at Work, University of Pennsylvania, Pennsylvania, USA, 2014.

[5] S. Isaacs (January 2015), "The Difference between Gamification and Game-based Learning. Association for Supervision and Curriculum Development Service", Available: http:// inservice.ascd.org /the-difference-between-gamification-and- game-based learning.

[6] S. Rogers, Swipe This!: The Guide to Great Touch Game Design, John Wiley and Sons Ltd. West Sussex, United Kingdom, 2012.

[7] T. Ozuorcon and F. Tabak (December 2012), "Is m-Learning versus e- Learning or are They Supporting Each Other", Available: https://www.researchgate.net/publication/257716228_ is_m-learning_versus_e-learning_or_are_they_supporting_each_other/

[8] W.H. Yuang and D. Soman (December 2013), “A Practictioner's Guide to Gamification of Education”, Available: https://www.researchgate.net/publication/257716228/inside.rotman.utoronto.ca/ behaviouraleconomicsinaction/ files/2013/09/guidegamifacatinoeducationdec2013.pdf 